\title{
Genetic and Physiological Evidence That Oligodendrocyte Gap Junctions Contribute to Spatial Buffering of Potassium Released during Neuronal Activity
}

\author{
Daniela M. Menichella, ${ }^{1,5 *}$ Marta Majdan, ${ }^{1 \star}$ Rajeshwar Awatramani, ${ }^{3}$ Daniel A. Goodenough, ${ }^{2}$ Erich Sirkowski, ${ }^{4}$ \\ Steven S. Scherer, ${ }^{4}$ and David L. Paul ${ }^{1}$ \\ Departments of ${ }^{1}$ Neurobiology and ${ }^{2}$ Cell Biology, Harvard Medical School, Boston, Massachusetts 02115, ${ }^{3}$ Department of Neurology and Center for Genetic \\ Medicine, Northwestern University, Chicago, Illinois 60611, ${ }^{4}$ Department of Neurology, The University of Pennsylvania School of Medicine, Philadelphia, \\ Pennsylvania 19104-6077, and 5Institute of Neurology, Instituto di Ricovero e Cura a Carattere Scientifico Ospedale Maggiore, Centro Dino Ferrari, \\ University of Milan, 20122 Milan, Italy
}

Mice lacking the $\mathrm{K}^{+}$channel Kir4.1 or both connexin32 (Cx32) and $\mathrm{Cx} 47$ exhibit myelin-associated vacuoles, raising the possibility that oligodendrocytes, and the connexins they express, contribute to recycling the $\mathrm{K}^{+}$evolved during neuronal activity. To study this possibility, we first examined the effect of neuronal activity on the appearance of vacuoles in mice lacking both $\mathrm{Cx} 32$ and $\mathrm{Cx} 47$. The size and number of myelin vacuoles was dramatically increased when axonal activity was increased, by either a natural stimulus (eye opening) or pharmacological treatment. Conversely, myelin vacuoles were dramatically reduced when axonal activity was suppressed. Second, we used genetic complementation to test for a relationship between the function of Kir4.1 and oligodendrocyte connexins. In a Cx32-null background, haploinsufficiency of either $\mathrm{Cx} 47$ or Kir4.1 did not affect myelin, but double heterozygotes developed vacuoles, consistent with the idea that oligodendrocyte connexins and Kir4.1 function in a common pathway. Together, these results implicate oligodendrocytes and their connexins as having critical roles in the buffering of $\mathrm{K}^{+}$released during neuronal activity.

Key words: demyelination; oligodendrocyte; gap junction; connexin; potassium channel; astrocyte

\section{Introduction}

Connexins, the channel-forming components of gap junctions, are critical for normal myelination in both CNS and PNS. Myelinating cells in both cases express multiple connexins, including connexin32 (Cx32) (Scherer et al., 1995), Cx47 (Menichella et al., 2003; Odermatt et al., 2003), and Cx29 (Altevogt et al., 2002; Nagy et al., 2003). In humans, CX32 (gene GJB1) mutations cause X-linked Charcot-Marie-Tooth disease (Bergoffen et al., 1993), a demyelinating neuropathy predominantly affecting the PNS with occasional CNS involvement (Taylor et al., 2003), whereas Cx47 (gene GJA12) mutations cause abnormal CNS myelin in Pelizaeus-Merzbacher-like disease (Uhlenberg et al., 2004). In mice, loss of either $\mathrm{Cx} 32$ or $\mathrm{Cx} 47$ causes less prominent abnormalities than those observed in humans, but double knock-outs (dKOs) of both connexin genes results in profound CNS dysmyelination and early mortality (Menichella et al., 2003; Odermatt et al., 2003). Although both Schwann cells (SCs) and oligodendrocytes (OLs) require connexins, they are used in different ways. In myelinating SCs, Cx32 forms reflexive gap junctions between

\footnotetext{
Received Jan. 23, 2006; revised Sept. 7, 2006; accepted Sept. 11, 2006.

This work was supported by National Institutes of Health Grants GM37751 (D.L.P.), GM18974 (D.A.G.), and NS42878 and NS43560 (S.S.S.). We thank Dr. Klaus Willecke for the CX32 mutant mice.

*D.M.M. and M.M. contributed equally to this work.

Correspondence should be addressed to David L. Paul, Department of Neurobiology, Harvard Medical School, 220 Longwood Avenue, Boston, MA 02115. E-mail: dpaul@hms.harvard.edu.

DOI:10.1523/JNEUROSCI.0304-06.2006

Copyright $\odot 2006$ Society for Neuroscience $\quad$ 0270-6474/06/2610984-08\$15.00/0
}

adjacent layers of the myelin sheath, likely linking the cell body to its periaxonal cytoplasm (Balice-Gordon et al., 1998), but does not participate in gap junctions with other cells. In contrast, ultrastructural studies have shown that myelinating OLs form extensive gap junctions with astrocytes (Massa and Mugnaini, 1982; Waxman and Black, 1984; Rash et al., 2001; Kamasawa et al., 2005).

A possible role for junctions between OLs and astrocytes could be to facilitate absorption and removal of extracellular $\mathrm{K}^{+}$ released during neuronal activity. It has been proposed (Orkand et al., 1966) that the strongly negative resting potential and relatively high permeability to $\mathrm{K}^{+}$typical of astrocytes could result in uptake of $\mathrm{K}^{+}$when the extracellular concentration was high, i.e., after extensive neuronal activity. Gap junctions could facilitate the diffusion of the absorbed $\mathrm{K}^{+}$into available sinks, such as local capillaries, by providing an intracellular pathway for dispersion. The "spatial buffer" theory as originally proposed only involved a network of highly coupled astrocytes. However, inclusion of oligodendrocytes into the network might improve its spatial buffering capacity. In support of this hypothesis, there is a striking similarity in the phenotypes of the $\mathrm{Cx} 32 / \mathrm{Cx} 47 \mathrm{dKO}$ and the knock-out of Kir4.1, an inwardly rectifying $\mathrm{K}^{+}$channel (Neusch et al., 2001). Kir4.1 is highly enriched at the perivascular end feet of astrocytes (Kalsi et al., 2004) and is known to be an important contributor to $\mathrm{K}^{+}$homeostasis in the CNS (for review, see $\mathrm{Ne}$ usch et al., 2003). Both Cx32/Cx47 and Kir4.1 KOs display a characteristic vacuolation of myelin not associated with mutations in other murine myelin genes. Another unique feature of 
the $\mathrm{Cx} 32 / \mathrm{Cx} 47 \mathrm{dKO}$ is strong region-specific differences in demyelination, which are not seen in other animal models of demyelination. For example, fiber disruption in the $\mathrm{dKO}$ pons and optic nerve was severe, whereas corticospinal tract and trigeminal nerve were relatively spared (Menichella et al., 2003). Higher levels of activity in some regions (i.e., more $\mathrm{K}^{+}$release) could lead to local pathological changes.

To test the hypothesis that oligodendrocyte gap junctions are important in buffering $\mathrm{K}^{+}$released during axonal activity, we monitored vacuolation in the $\mathrm{Cx} 32 / \mathrm{Cx} 47 \mathrm{dKO}$ in experimental paradigms in which axonal activity is either suppressed or increased. In both cases, the vacuolated pathology is remarkably well correlated with axonal activity. Additional support for a role of $\mathrm{OL}$ in $\mathrm{K}^{+}$buffering was provided by genetic complementation. Whereas neither $\mathrm{Cx} 47$ nor Kir4.1 heterozygotes display any abnormal phenotypes in a Cx32-null background, Kir4.1/Cx47 compound heterozygotes develop myelin vacuoles. Together, these data suggest that Kir4.1 and the connexins function in a common pathway to regulate $\mathrm{CNS} \mathrm{K}^{+}$.

\section{Materials and Methods}

Mice. Cx32/Cx47 dKOs were obtained and genotyped as described previously (Menichella et al. 2003). Kir4.1 heterozygous mice were obtained from Taconic (Germantown, NY) and genotyped as described previously (Neusch et al., 2001). For genetic complementation studies, $C \times 32^{-/-}$, $\mathrm{C} \times 47^{+/-}$females were crossed to Kir4.1 $1^{+/-}$males. F1 offspring harboring the following genotypes were selected for study: $C \times 32^{-/ Y}, C \times 47^{+/-}$, Kir4.1 $1^{+/-} ; C x 32^{-/ Y}, C x 47^{+/-}$, Kir4.1 $1^{+/+} ; C x 32^{-/ Y}, C x 47^{+/+}$, Kir4.1 $^{+/-}$; $\mathrm{C} \times 32^{+/-}, \mathrm{Cx} 47^{+/+}, \mathrm{Kir}_{1} 1^{+/-}$, as well as Cx32 $2^{+-}, \mathrm{C} \times 47^{+/-}, \mathrm{Kir}_{1} 1^{+/-}$.

Tetrodotoxin/cholera toxin injections and surgical procedures. Intraocular tetrodotoxin (TTX) injections were performed as described previously (Stryker and Harris, 1986; Corriveau et al., 1998; Lein and Shatz, 2000). Postnatal day 11 (P11) mice were anesthetized with an isofluorane/ $\mathrm{O}_{2}$ mixture, and $2 \mu \mathrm{l}$ of $100 \mu \mathrm{M}$ TTX (Calbiochem, San Diego, CA) dissolved in $0.9 \% \mathrm{NaCl}$ was injected intraocularly with a 30 gauge needle into the posterior chamber. The TTX injection was repeated $48 \mathrm{~h}$ later, and the mice were killed at P15 (four dKO animals and two WT animals). Cholera toxin injections were performed following previously published protocols (Penn et al., 1998). P9 animals were anesthetized with an isofluorane $/ \mathrm{O}_{2}$ mixture, the fused eyelid was opened, and $2 \mu \mathrm{l}$ of 0.125 $\mu \mathrm{g} / \mathrm{ml}$ cholera toxin (Sigma, St. Louis, $\mathrm{MO}$ ) in $0.9 \% \mathrm{NaCl}$ was injected with a 30 gauge needle into the posterior chamber of the eye. The animals (four dKO and two WT) were then killed at P11. At the conclusion of both (TTX and cholera toxin) experiments, the mice were killed with chloral hydrate, and the visual cortex and optic nerves were processed for RNA and histological analyses, respectively.

Semithin sections and quantitation of vacuolation in optic nerve. The optic nerve from injected side and contralateral uninjected eyes were removed from the globe to the chiasm, fixed [2.5\% paraformaldehyde, $3 \%$ glutaraldehyde in $0.1 \mathrm{~m}$ phosphate buffer (PB), $\mathrm{pH}$ 7.4] overnight at $4^{\circ} \mathrm{C}$ rinsed in $\mathrm{PB}$, postfixed in $2 \% \mathrm{OsO}_{4}$ in $0.1 \mathrm{M} \mathrm{PB}$ for $1 \mathrm{~h}$, dehydrated in graded ethanols, infiltrated, and embedded in epoxy. Semithin sections were stained with toluidine blue. Spinal cord and optic nerve from other mutant mice

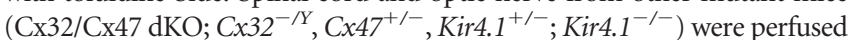
with fixative for optimal preservation, and the spinal cords were sliced into 1 -mm-thick pieces and fixed overnight. Electron microscopy was done as described previously (Menichella et al., 2003).

For quantitative analysis of vacuoles, we analyzed the optic nerves of four animals in each experimental group (TTX or cholera toxin injected); in each group, the uninjected eye served as a control. The optic nerve was examined at four different distances (each $\sim 500 \mu \mathrm{m}$ apart) from the eye to the chiasm, to minimize differences attributable to the different timing of myelination along the length of the optic nerve (Skoff et al., 1980). Five $1 \mu \mathrm{m}$ sections were counted at each of the four levels for each nerve. Qualitatively, vacuoles appeared to be distributed in a nonrandom manner, but no correlation with distance from the nerve head was evident. Blind analysis of the samples was attempted, but the often dramatic differences between experimental and control conditions compromised that effort. To minimize the effects of nonrandom distribution, we analyzed two different fields $(110 \times 80 \mu \mathrm{m})$ in each section. The numbers of vacuoles per field, the area of each vacuole, and total vacuolated area per field were measured using NIH ImageJ software (version $1.34 \mathrm{n}$ ). Vacuoles were arbitrarily subdivided into small $\left(<20 \mu \mathrm{m}^{2}\right)$ and large $(>20$ $\left.\mu \mathrm{m}^{2}\right)$. The values obtained at different levels [4 levels $\times 5$ sections $\times 2$ $(110 \times 80 \mu \mathrm{m})$ fields] were combined because there were no reproducible differences at these levels and normalized to a unit area of $0.1 \mathrm{~mm}^{2}$. Myelin sheaths per field were counted manually [ 4 levels $\times 2$ sections $\times 1(25 \times 25$ $\mu \mathrm{m})$ field], and data were normalized to a unit area of $0.1 \mathrm{~mm}^{2}$.

RNA preparation and real-time quantitative PCR analysis. Total RNA was isolated from visual cortex using Trizol (Invitrogen, Carlsbad, CA). cDNA was obtained using the iScript cDNA synthesis kit (Bio-Rad, Hercules, CA), and PCR oligonucleotide primers were designed using Primer3 software (Whitehead Institute for Biomedical Research, Cambridge, MA). The following primer sets were used for real-time PCR: brainderived neurotrophic factor (BDNF) sense, $5^{\prime}$ aaaagtcccggtatccaaagg $3^{\prime}$; BDNF antisense, $5^{\prime}$ cttatgaatcgccagcca at $3^{\prime}$; hypoxanthine phosphoribosyltransferase (HPRT) sense, $5^{\prime}$ tgctcgagatgtcatgaagg $3^{\prime}$; and HPRT antisense, $5^{\prime}$ tatgtccccottgactgat $3^{\prime}$.

Primer sets and subsequent PCR products were first evaluated by gel electrophoresis to determine whether a single PCR product of predicted size was generated. A typical real-time reaction mix contained $1 \times \mathrm{iQ}$ SYBR Green Supermix (Bio-Rad), $100 \mathrm{~nm}$ each oligonucleotide primers, and $10 \mathrm{ng}$ of cDNA in a $25 \mu \mathrm{l}$ total volume. The reaction was performed on a Smart Cycler system (Cepheid, Sunnyvale, CA). The relative amount of BDNF mRNA was normalized to the level of an internal control mRNA, HPRT (Thellin et al., 1999). Real-time PCR data analysis was performed according to the comparative threshold cycle $\left(\mathrm{C}_{\mathrm{T}}\right)$ method, which enables relative quantitation of template but eliminates the need for a standard curve. The $\mathrm{C}_{\mathrm{T}}$ value is the cycle at which a significant increase in SYBR Green fluorescence is first detected (exceeds an arbitrary threshold). The calculation for the quantitation starts with obtaining the difference $\left(\Delta \mathrm{C}_{\mathrm{T}}\right)$ between the $\mathrm{C}_{\mathrm{T}}$ values of the target (BDNF) and the normalizer (HPRT) as follows: $\Delta \mathrm{C}_{\mathrm{T}}=\mathrm{C}_{\mathrm{T}}$ (target) $-\mathrm{C}_{\mathrm{T}}$ (normalizer). For each animal, this value is calculated for both experimental sample (visual cortex contralateral to the TTX/cholera toxin injection) and control sample (cortex ipsilateral to the injection). The comparative $\Delta \Delta \mathrm{C}_{\mathrm{T}}$ calculation used in determining gene expression involves finding the difference between the $\mathrm{C}_{\mathrm{T}}$ of each experimental sample and the $\Delta \mathrm{C}_{\mathrm{T}}$ of the control for each cortex pair. The last step in the quantitation is to transform these values into absolute values according to the following formula: $\mathrm{CEL}=2^{-\Delta \Delta \mathrm{CT}}$, where CEL is comparative expression level. Because SYBR Green intercalates all double-stranded DNA (including primer dimers), all real-time PCR runs included a melt curve for product identification and purity (for details, see the Smart Cycler Operator Manual), and only reactions that resulted in a single product were considered valid.

To evaluate the significance of changes in BDNF ratios, each experiment included a cohort of age- and genotype-matched mice in which no pharmacologic manipulation was performed. The ratios of contralateral and ipsilateral BDNF levels for animals injected with TTX averaged $0.73 \pm 0.15(n=4)$, whereas the ratios for controls averaged $1.00 \pm 0.08(n=3)$. A two-tailed $t$ test performed on these groups indicated a significant difference $(p=0.039)$. Ratios for mice injected with cholera toxin averaged $1.75 \pm 0.31(n=4)$, whereas controls averaged $1.01 \pm 0.12(n=3)$. For these groups, the twotailed $t$ test also shows a significant difference $(p=0.0127)$.

\section{Results}

\section{Vacuolation in Cx32/Cx47 dKO optic nerves increases after eye-opening}

Region-specific hypomyelination and vacuolation are the most pronounced pathological findings in $\mathrm{Cx} 32 / \mathrm{Cx} 47 \mathrm{dKO}$ mice (Menichella et al., 2003; Odermatt et al., 2003). Vacuolation is characterized by enlarged extracellular space between axons and their myelin sheaths. We tested the hypothesis that these changes depend on levels of neuronal activity using the optic nerve, which is well characterized with respect to myelination, and is severely 

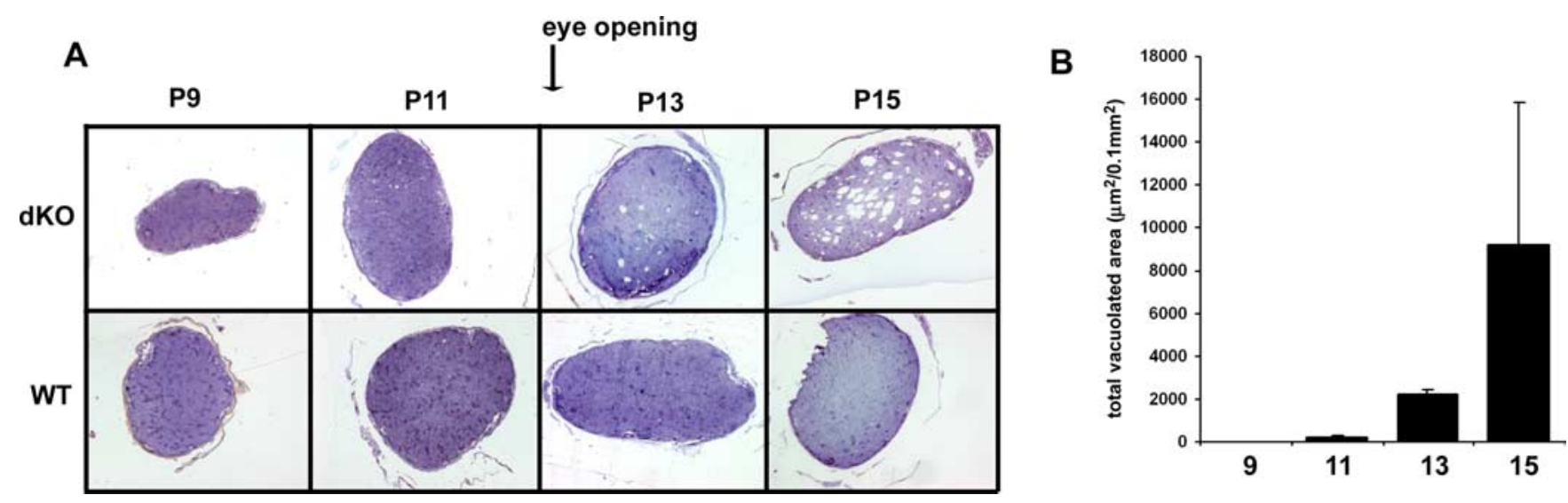

Figure 1. Massive vacuolation in the $\mathrm{Cx} 32 / \mathrm{Cx} 47 \mathrm{dK} 0$ optic nerves coincides with eye-opening. $\boldsymbol{A}$, Toluidine blue-stained semithin sections of optic nerves from dKO mice and their WT littermates at the indicated ages. Scale bar, $100 \mu \mathrm{m}$. B, Quantification of total vacuolated area $\left(\mu \mathrm{m}^{2} / 0.1 \mathrm{~mm}^{2}\right)$ in $\mathrm{dKO}$ optic nerves. Error bars indicate SEM.

affected in $\mathrm{dKO}$ mice. Furthermore, eye opening at P12-P14 provides a natural stimulus that increases retinal ganglion cell (RGC) activity (Bansal et al., 2000), and, most importantly, it is possible to pharmacologically manipulate axonal activity in the optic nerve.

To determine whether retinal activity driven by natural stimuli correlates with increased vacuolation, we compared the morphology of dKO and wild-type (WT) optic nerves before and during the period of eye opening. At $\mathrm{P} 9, \mathrm{dKO}$ and $\mathrm{WT}$ optic nerves were indistinguishable: there were no myelinated axons and no vacuoles (Fig. 1A). At P11, some myelinated axons were evident in the WT and the $\mathrm{dKO}$; a few, small vacuoles were detected in the $\mathrm{dKO}$. The number and the size of the vacuoles increased dramatically by P13 and were even greater at P15, paralleling the increased density of myelinated axons. Morphometric analysis documents a 40-fold increase in the vacuolated area in the dKO between P9 and P15 (Fig. $1 B$ ). The increase in RGC activity after eye opening was correlated with higher levels of BDNF mRNA expression in visual cortex, as assessed by means of quantitative reverse transcription-PCR (Schoups et al., 1995; Lein and Shatz, 2000): between P11 and P15 (data not shown), BDNF transcript levels increase by approximately threefold (data not shown), in agreement with published data (Castren et al., 1992). Thus, eye opening and the resultant naturally occurring increase in RGC activity correlate well with the appearance of vacuoles.

Decreasing RGC activity diminishes the vacuolated pathology We next tested whether decreasing axonal activity would reduce the pathology in dKO optic nerves. To completely block RGC activity in one eye, TTX was monocularly injected at P11, before the development of significant vacuolation, and an additional injection was performed on P13 (Stryker and Harris, 1986). The corresponding treated and control optic nerves and bilateral primary visual cortex were harvested at P15. Vacuolation was assessed morphometrically in semithin sections of nerve, and BDNF transcript levels in the corresponding visual cortex was used as a molecular readout of RGC activity (Fig. $2 \mathrm{~A}$ ).

The extent of vacuolation in the optic nerve associated with the injected eye was dramatically reduced compared with that in the contralateral control. In particular, the density of large $(>20$ $\left.\mu \mathrm{m}^{2}\right)$ but not small $\left(<20 \mu \mathrm{m}^{2}\right)$ vacuoles was strikingly less in TTX-injected eyes (Fig. 2B). Electron microscopy (data not shown) confirmed that the vacuoles in the optic nerve typically separated the axons from their myelin sheaths, as reported previously for the $\mathrm{Cx} 32 / \mathrm{Cx} 47$ knock-out (Menichella et al., 2003;
A

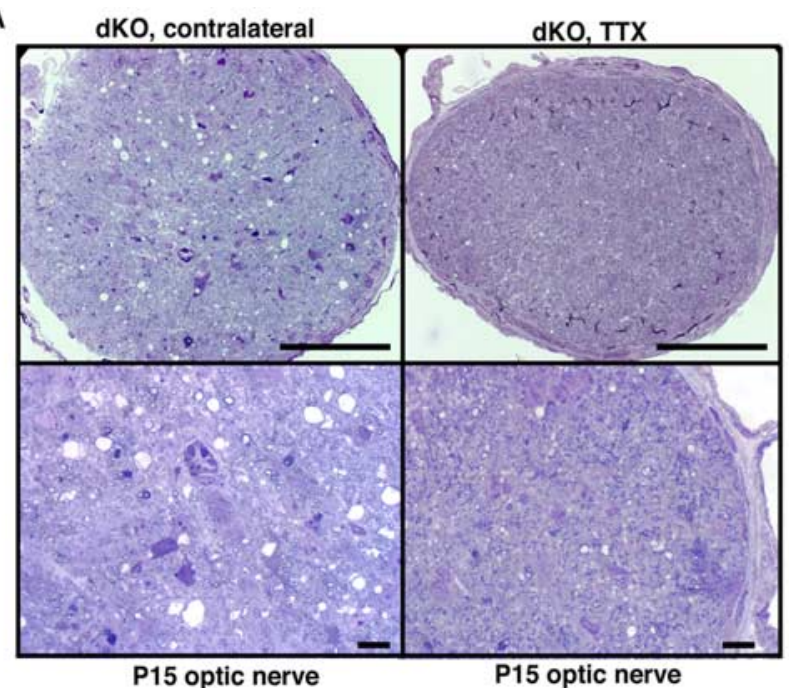

B

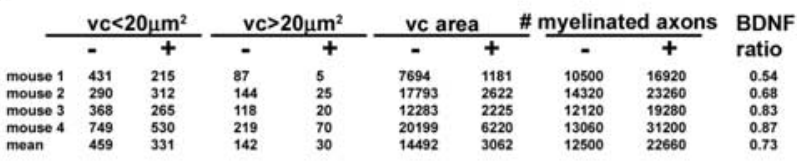

C
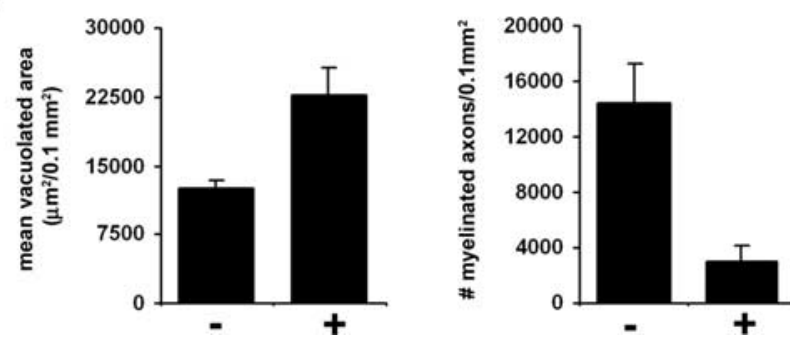

Figure 2. Vacuolation in $\mathrm{C} \times 32 / \mathrm{C} \times 47 \mathrm{dKO}$ optic nerves is reduced when axonal activity is suppressed. Intraocular injections of TTX were performed at P11 and P13; optic nerves and primary visual cortex were harvested at $P 15$. $A$, Semithin sections from the optic nerve associated with an injected eye reveal a dramatic reduction in vacuolation compared with the contralateral control nerve. Scale bars: top row, $100 \mu \mathrm{m}$; bottom row, $10 \mu \mathrm{m}$. B, Quantification of small $\left(<20 \mu \mathrm{m}^{2}\right)$ and large $\left(>20 \mu \mathrm{m}^{2}\right)$ vacuoles, as well as the total vacuolated area $\left(\mu \mathrm{m}^{2}\right)$ $0.1 \mathrm{~mm}^{2}$ ) and the number of myelinated axons (per $0.1 \mathrm{~mm}^{2}$ ) in TTX-injected $(+)$ and -uninjected/contralateral ( - ) optic nerves. The BDNF mRNA levels were normalized to HPRT mRNA and are presented as a ratio of contralateral injected visual cortex/contralateral uninjected visual cortex. Error bars indicate SEM. TTX injections result in fewer vacuoles, a reduction in total vacuolated area, and lower BDNF mRNA ratios. 
Odermatt et al., 2003). To rule out the possibility that TTX might reduce the number of vacuoles indirectly, by reducing the number of myelinated fibers (Demerens et al., 1996), we measured the density of myelinated fibers in each nerve. As shown in Figure $2 B$, the density tended to be higher in the optic nerves from TTXtreated eyes, thus eliminating this possibility. Finally, BDNF mRNA levels in primary visual cortex contralateral to the TTXinjected eye were significantly reduced (Fig. 2 B), confirming suppressed RGC activity. Thus, activity blockade produced a significant amelioration of the $\mathrm{dKO}$ pathology.

\section{Increasing activity exacerbates vacuolation in the $\mathrm{dKO}$ optic nerve}

The relationship between the $\mathrm{dKO}$ pathology and neuronal activity was further evaluated by pharmacologically increasing RGC activity with cholera toxin (Stellwagen and Shatz, 2002). Cholera toxin was injected intraocularly at P9, a stage at which few if any vacuoles are present in the $\mathrm{dKO}$, and optic nerves and primary visual cortex were harvested at P11. As shown in Figure $3 A$, an increase in the size and number of vacuoles is readily apparent in nerves associated with the injected eye. Quantitative analysis revealed increased density of both small $\left(<20 \mu \mathrm{m}^{2}\right)$ and large $(>20$ $\mu \mathrm{m}^{2}$ ) vacuoles compared with contralateral controls (Fig. $3 B$ ), and the total vacuolated area was increased sevenfold (Fig. $3 C$ ). BDNF mRNA levels were increased by $50-100 \%$ in the visual cortex contralateral to the injected eye, confirming increased RGC activity (Fig. 3B). Because cholera toxin decreased the density of myelinated axons (Fig. $3 C$ ), it is unlikely to have accelerated myelination and thus the development of vacuoles. Furthermore, intraocular injection of P9 WT mice with cholera toxin with an identical regimen did not cause any vacuolation of the optic nerve (data not shown). As in the case of TTX, electron microscopy revealed no significant ultrastructural differences between vacuoles in cholera toxin-treated and untreated dKOs (data not shown). Together, these data show that decreases and increases in RGC activity have opposite effects on the dKO pathology.

\section{Genetic evidence that Kir4.1 channels and oligodendrocyte gap junctions function in a common pathway}

Vacuolated myelin is an unusual phenotype but has also been reported in mice lacking the inwardly rectifying potassium channel Kir4.1, which is expressed in both oligodendrocytes and astrocytes (Neusch et al., 2001). Because the precise relationship of the vacuoles in Kir4.1-null mice to myelin sheaths has not been extensively characterized, we performed an ultrastructural examination in P9 or P10 Kir4.1-null mice, just before the animals become moribund (Neusch et al., 2001). Semithin sections showed abundant vacuoles in the spinal cord white matter of all Kir4.1 $1^{-/-}(n=5)$ mice (Fig. $\left.4 B\right)$ but not Kir4.1 $1^{+/-}$littermates $(n=7)$ (Fig. $4 A)$. Vacuoles were rare in spinal cord gray matter and were not present in optic nerve, nor were there myelinated axons in these locations at this early postnatal age (data not shown).

Electron microscopy of Kir4.1 $1^{-/-}$spinal cords $(n=3)$ revealed that vacuoles were generally associated with the outer aspect of myelin sheaths (Fig. $4 C, D, F$, arrowheads). Even without reconstructing vacuoles in three dimensions, in single cross sections, a myelin sheath formed a part of the perimeter in $82 \%$ of vacuoles (37 of 45). Rarely, vacuoles were observed separating the axon from sheath (Fig. $4 E$ ). This is a different pattern than we observed in the $\mathrm{Cx} 32 / \mathrm{Cx} 47 \mathrm{dKO}$, in which the vacuoles generally occur in the perixonal space (Menichella et al., 2003). In addition to vacuolation, we observed apoptotic cells with the ultrastructural features of oligodendrocytes (no intermediate filaments,
A

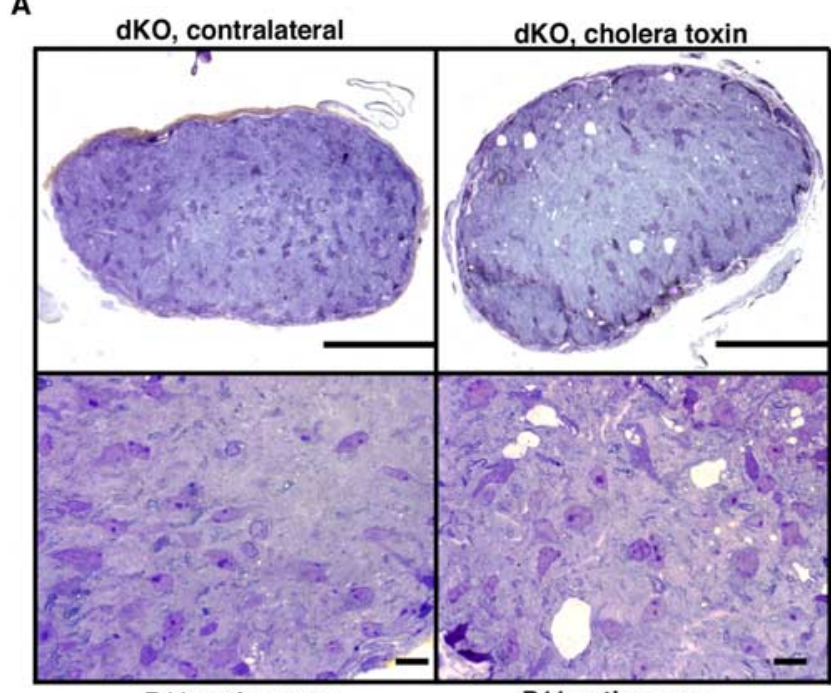

P11 optic nerve

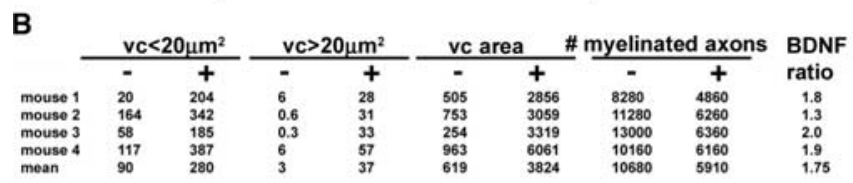

C
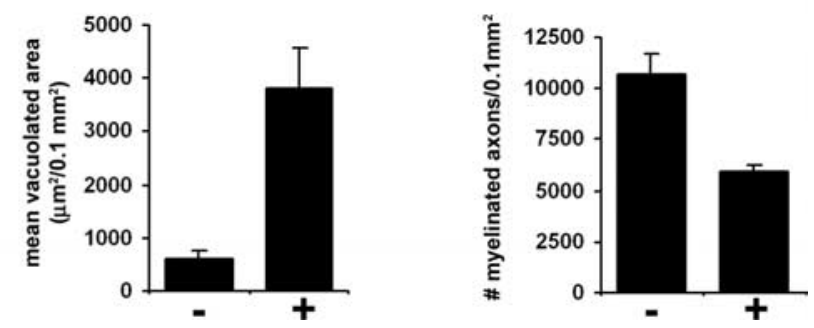

Figure 3. Vacuolation in $\mathrm{C} \times 32 / \mathrm{C} \times 47 \mathrm{dK} 0$ optic nerves is increased when axonal activity is stimulated. Intraocular injections of cholera toxin were performed at P9; optic nerves and visual cortex were harvested at P11. A, Optic nerves associated with the injected eye show a dramatic increase in vacuolation. Scale bars: top row, $100 \mu \mathrm{m}$; bottom row, $10 \mu \mathrm{m}$. B, Quantification of small $\left(<20 \mu \mathrm{m}^{2}\right)$ and large $\left(>20 \mu \mathrm{m}^{2}\right)$ vacuoles, total vacuolated area $\left(\mu \mathrm{m}^{2} / 0.1 \mathrm{~mm}^{2}\right)$, and the number of myelinated axons per $0.1 \mathrm{~mm}^{2}$ optic nerve, from cholera toxin-injected $(+)$ and contralateral ( - ) eyes, as well as the BDNF mRNA ratio. Cholera toxin injections result in more vacuoles, an increase in vacuolated area, and higher BDNF mRNA levels.

abundant ribosomes) in one of the mice (Fig. $4 F$, compare with oligodendrocyte with normal appearance in $D$ ). Together, these results confirm that Kir4.1 $1^{-1-}$ mice have vacuoles associated with CNS myelin and suggest that the vacuoles arise in conjunction with myelination.

Kir4.1 has a well documented role in buffering of $\mathrm{K}^{+}$generated during axonal activity (Newman, 1986; Kofuji and Newman, 2004). Although vacuoles in Kir4.1-null mice have a different location relative to the myelin sheath than those in connexin $\mathrm{dKO}$, our findings suggest that connexins also have a role in $\mathrm{K}^{+}$ buffering. To explore the idea that connexins and Kir4.1 function in a common pathway, we looked for a genetic interaction: if they function in a common pathway, then partial but coordinate reductions in the levels of $\mathrm{Cx} 32, \mathrm{Cx} 47$, and Kir4.1 could result in vacuolation. Therefore, we produced compound heterozygotes of $C \times 47$ and Kir4.1 in a Cx32-null background $\left(C \times 32^{-/ Y}\right.$, $C \times 47^{+/-}$, Kir4.1 $\left.1^{+/-} ; n=5\right)$. Vacuolation was evaluated in the spinal cord because vacuoles were not detected in optic nerves of 
P10 Kir4.1-null mice. Unlike Cx32/Cx47 $\mathrm{dKO}$ animals, which develop a severe tremor, seizures, and die within the first few postnatal weeks, these mice display no gross behavioral abnormalities. However, when their spinal cords were examined between 4 and 8 weeks of age, abundant vacuoles were observed, mostly in the gray matter (Fig. 5C). Ultrastructural examination $(n=3)$ demonstrated that vacuoles appeared to be associated with the outer aspect of myelin sheaths. In single cross sections, a myelin sheath forms part of the circumference of $95 \%$ ( 40 of 42 ) of the vacuoles (Fig. $5 F)$. Thus, the vacuoles are similar to those found in the Kir4.1-null mice rather than the connexin $\mathrm{dKO}$, which are typically located between the axon and its myelin sheath (Menichella et al., 2003; Odermatt et al., 2003).

Triple heterozygotes $\left(\mathrm{C} \times 32^{+/-}\right.$, C $x 47^{+/-}$, Kir4.1 $1^{+/-}$) develop vacuoles (Fig. $5 A$ ) but not nearly as many as in the $C \times 32^{-/ Y}$ background (CX32-/Y, Cx47 $7^{+/-}$, Kir4.1 $\left.1^{+/-}\right)$. Interpretation of $\mathrm{Cx} 32$ gene dosage effects are complicated by $\mathrm{X}$-chromosome inactivation, which produces some oligodendrocytes with normal levels of $\mathrm{Cx} 32$ and others with none. The mild phenotype in the triple heterozygote could result from compensation of null oligodendrocytes by normal ones. In any case, vacuoles were not detected in C $\times 32^{-/ Y}, C \times 47^{+/-}$, Kir4.1 $1^{+/+}$(Fig. 5B) or $\mathrm{C} \times 32^{+/-}, \mathrm{C} \times 47^{+/+}, \mathrm{Kir} 4.1^{+/-}$(data not shown) spinal cords. Regardless of the location of the vacuoles, these data establish an epistatic relationship between connexin and Kir4.1 genes, consistent with the hypothesis that OL connexins and Kir4.1 function in a common pathway.

\section{Discussion}

Both Kir4.1 and connexin knock-outs display myelin-associated vacuoles, raising the possibility that oligodendrocytes, and the connexins they express, contribute to recycling the $\mathrm{K}^{+}$evolved during neuronal activity. We tested this hypothesis using two independent approaches. First, we examined the effect of neuronal activity on the appearance of vacuoles in mice lacking oligodendrocyte connexins. We found that the size and number of vacuoles dramatically increased when axonal activity was increased, by either a natural stimulus (eye opening) or pharmacological treatment (intraocular injection of cholera toxin). Conversely, we found that vacuoles were dramatically reduced when axonal activity was suppressed by injection of TTX. Second, we used genetic complementation to test for a relationship between the function of the Kir4.1 and oligodendrocyte connexins. In a Cx32-null background, haploinsufficiency of either $\mathrm{Cx} 47$ or Kir4.1 did not affect the structural integrity of myelin sheaths, but double heterozygotes developed vacuoles, consistent with the idea that oligoden-
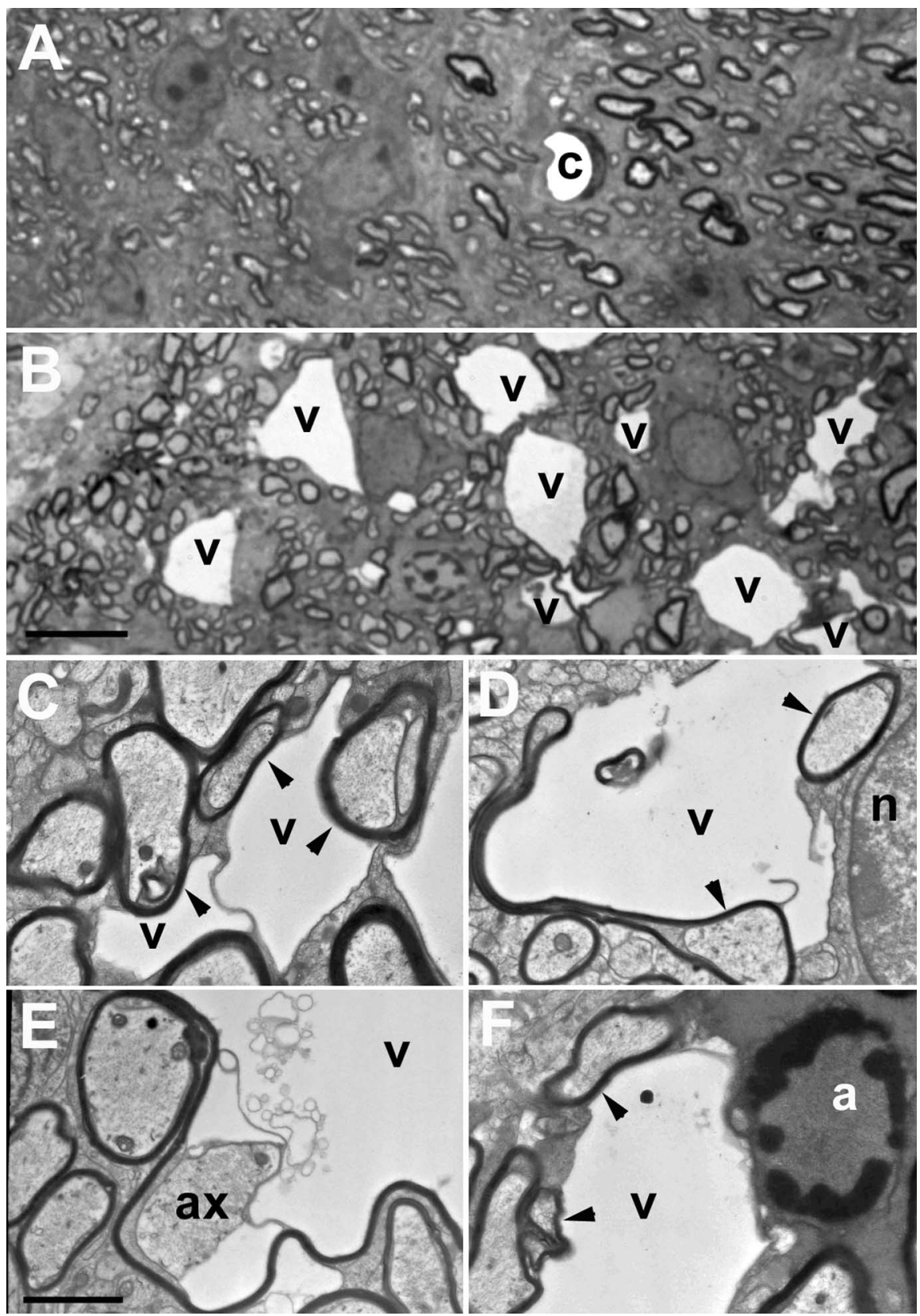

Figure 4. Pathological findings in Kir4.1-null mice. These are images of transverse sections of P10 spinal cords from Kir4.1-null mice or their WT littermates. Semithin sections show abundant vacuoles (v) in the white matter of Kir4.1-null (B) but not WT $(\boldsymbol{A})$ spinal cords, in which a capillary (c) is indicated. $\boldsymbol{C}-\boldsymbol{F}$, Electron micrographs of Kir4.1-null white matter. $\boldsymbol{C}, \boldsymbol{D}, \boldsymbol{F}$, Typical vacuoles that are associated with sheaths (arrowheads). $\boldsymbol{E}$, An atypical vacuole that separates an axon (ax) from its myelin sheath. $\boldsymbol{D}$, Part of a normal appearing oligodendrocyte (n). $\boldsymbol{F}$, Part of an apoptotic oligodendrocyte (a). Scale bars: $\boldsymbol{A}, \boldsymbol{B}, 10 \mu \mathrm{m}, \boldsymbol{C}-\boldsymbol{F}, 1 \mu \mathrm{m}$.

drocyte connexins and Kir4.1 function in a common pathway. Together, these results suggest that oligodendrocytes and their connexins have critical roles in the buffering of $\mathrm{K}^{+}$released during neuronal activity.

The notion that astrocytes could serve as "spatial buffers" of $\mathrm{K}^{+}$was first suggested by Orkand et al. (1966). They showed that stimulation of amphibian optic nerve caused a slow, transient depolarization of glial cells. They proposed the depolarization was caused by an increase in extracellular $\left[\mathrm{K}^{+}\right]$attributable to neuronal activity and that astrocytes, by virtue of their high permeability to $\mathrm{K}^{+}$and their extensive electrical coupling, could spatially buffer $\mathrm{K}^{+}$by redistributing it from areas of high extracellular concentration to areas in which the extracellular concen- 

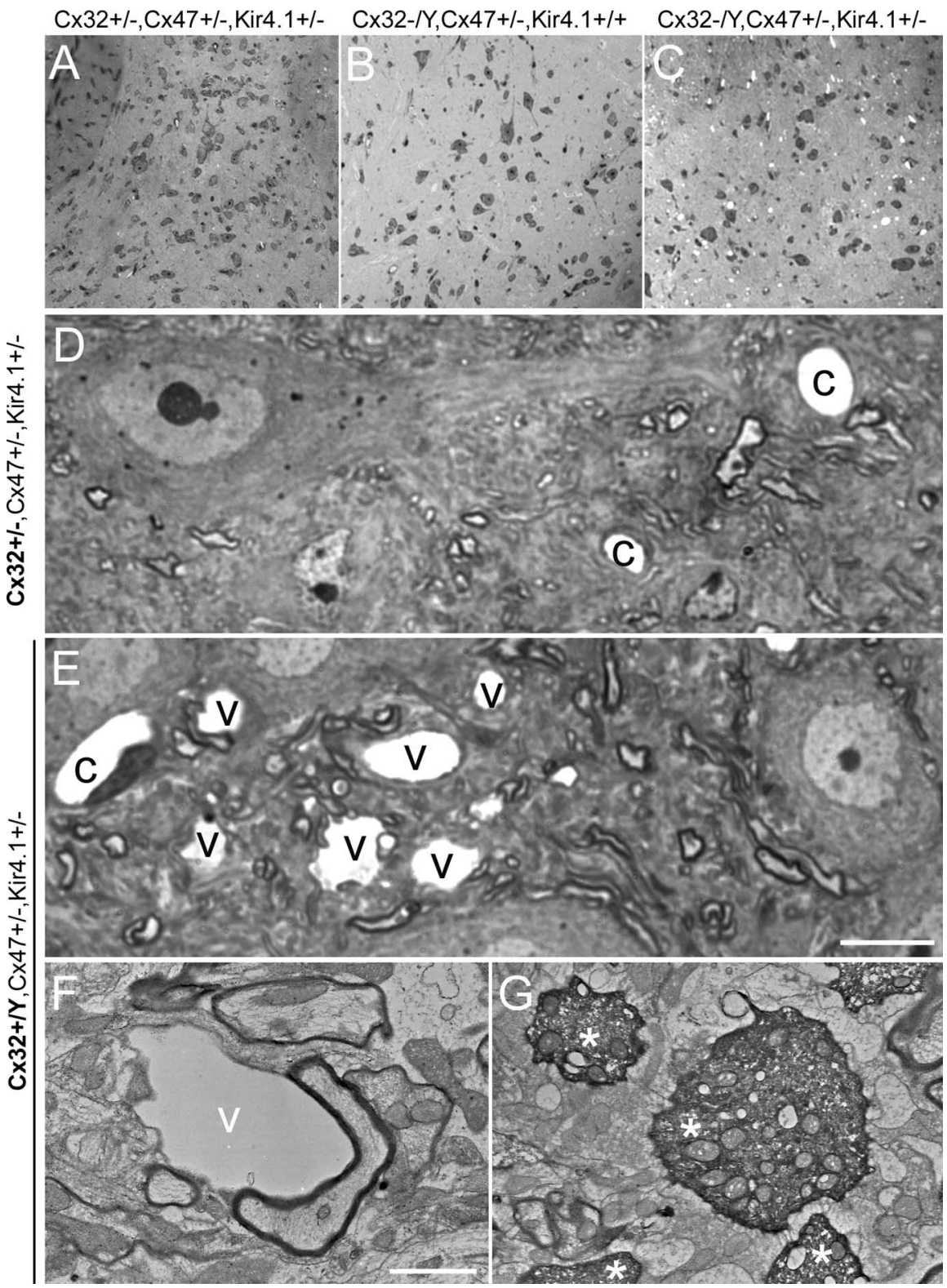

Figure 5. Genetic evidence that Kir4.1 channels and gap junctions function in a common pathway: pathological findings in $C \times 32^{-/ Y}, C \times 47^{+/-}, K i r 4.1^{+/-}$spinal cords. Low-magnification images of toluidene blue-stained semithin transverse sections of spinal cord gray matter reveal the extent of vacuolation in $C \times 32^{-/ Y}, C \times 47^{+/-}, K i r 4.1^{+/-}$mice $(\boldsymbol{C})$ but not in controls $(\boldsymbol{A}, \boldsymbol{B})$. D-G, These are images of transverse sections of spinal cord gray matter from 5 -week-old mice. Capillaries $(c)$ but not vacuoles $(v)$ are present in this field from a $\mathrm{C} \times 32^{+/-}, \mathrm{C} \times 47^{+/-}$, Kir4.1 $1^{+/-}(\boldsymbol{D})$, but vacuoles are abundant in $\mathrm{C} \times 32^{-/ Y}, \mathrm{C} \times 47^{+/-}, \mathrm{Kir}^{+} 1^{+/-}$ $(\boldsymbol{E}-\boldsymbol{G})$ spinal cords. Electron microscopy shows a typical vacuole that is partly surrounded by a myelin sheath $(\boldsymbol{F})$, as well as electron-dense cellular processes (G; asterisks), which are also a feature of this genotype. Scale bars: $\boldsymbol{A}, \boldsymbol{B}, 10 \mu \mathrm{m} ; \boldsymbol{C}, \boldsymbol{D}, 1 \mu \mathrm{m}$.

tration was lower, without any net change in glial intracellular $\left[\mathrm{K}^{+}\right]$. This spatial buffering hypothesis was widely accepted and ramifications of the hypothesis were extensively explored in mammalian astrocytes (Connors et al., 1982; Ransom et al., 2000) and Muller glia (Newman, 1986; Kofuji and Newman, 2004). Several mechanisms to account for astrocyte $\mathrm{K}^{+}$uptake and release have been proposed, including $\mathrm{Na}, \mathrm{K}$-ATPases, ion cotransporters, and $\mathrm{K}^{+}$channels, especially Kir4.1 (Kofuji and Newman, 2004). In addition to these pumps, exchangers, and $\mathrm{K}^{+}$channels, astrocytes also express aquaporin-4, an $\mathrm{H}_{2} \mathrm{O}$ channel (Nielsen et al., 1997). Astrocytes swell when optic nerves are electrically stimulated, presumably because $\mathrm{H}_{2} \mathrm{O}$ diffusing through aquaporin channels follows altered ion gradients (MacVicar et al., 2002).
However, the classic model in which astrocytes are solely responsible for spatial buffering/siphoning does not fully consider the possible effects of myelination on $\mathrm{K}^{+}$redistribution. The amphibian optic nerve studied by Orkand et al. (1966) is essentially unmyelinated and $\mathrm{K}^{+}$release is likely not spatially restricted to particular regions of the axolemma. In contrast, myelination in rodent optic nerve is accompanied by a concentration of the voltagegated $\mathrm{K}^{+}$channels KCNQ2 and KCNQ3 into the nodal axolemma (Devaux et al., 2004; Pan et al., 2006) and Kv1.1 and Kv1.2 into the juxtaparanodal axolemma (Wang et al., 1993; Vabnick and Shrager, 1998). Furthermore, myelination is accompanied by dramatic decreases in the amount of extracellular $\mathrm{K}^{+}$detected during neuronal activity (Connors et al., 1982), in the extracellular volume (Ransom et al., 1985) and in the effects of $\mathrm{K}^{+}$ channel blockers (Devaux et al., 2002). Changes in $\mathrm{K}^{+}$channel distribution are likely in part responsible for those physiological changes. Consistent with the classic model, $\mathrm{K}^{+}$released through nodal channels could enter perinodal astrocytic processes for redistribution. However, $\mathrm{K}^{+}$released from juxtaparanodal channels would enter the periaxonal space between oligodendrocyte and axon and additional movement would be impeded by the paranodal axoglial junctions, which electrically isolate the nodal and internodal compartments (David et al., 1993; Arroyo and Scherer, 2000). The volume of the periaxonal compartment is limited and thus $\mathrm{K}^{+}$concentration in this space could be significantly higher than that measured using extracellular electrodes (Connors et al., 1982).

The fate of the $\mathrm{K}^{+}$accumulating in the periaxonal space is unknown. Figure 6 depicts several possible different routes for dispersal. Some $\mathrm{K}^{+}$might diffuse past the axoglial junctions or be removed by $\mathrm{Na}, \mathrm{K}$ ATPase (Ransom et al., 2000). One Na,KATPase isoform, $\alpha 3$, is localized on internodal axonal membranes (McGrail et al., 1991) and could promote axonal uptake. A different isoform, $\alpha 2$, is expressed by oligodendrocytes (Fink et al., 1996) and might facilitate import of $\mathrm{K}^{+}$into the periaxonal cytoplasm. Glial connexins could contribute to redistribution of $\mathrm{K}^{+}$from periaxonal cytoplasm is two ways. First, as suggested by Kamasawa et al. (2005) "reflexive" gap junctions between the layers of myelin at paranodes could dramatically shorten the distance for diffusion from the inner/adaxonal to the outer/abaxonal cytoplasm, as has been shown to be the case for myelinating Schwann cells (BaliceGordon et al., 1998). Second, gap junctions between astrocytes and oligodendrocytes could allow oligodendrocyte $\mathrm{K}^{+}$access to astrocyte cytosol. Finally, as proposed in the original spatial buffer hypothesis, extensive gap junctional coupling of astrocytes provides 


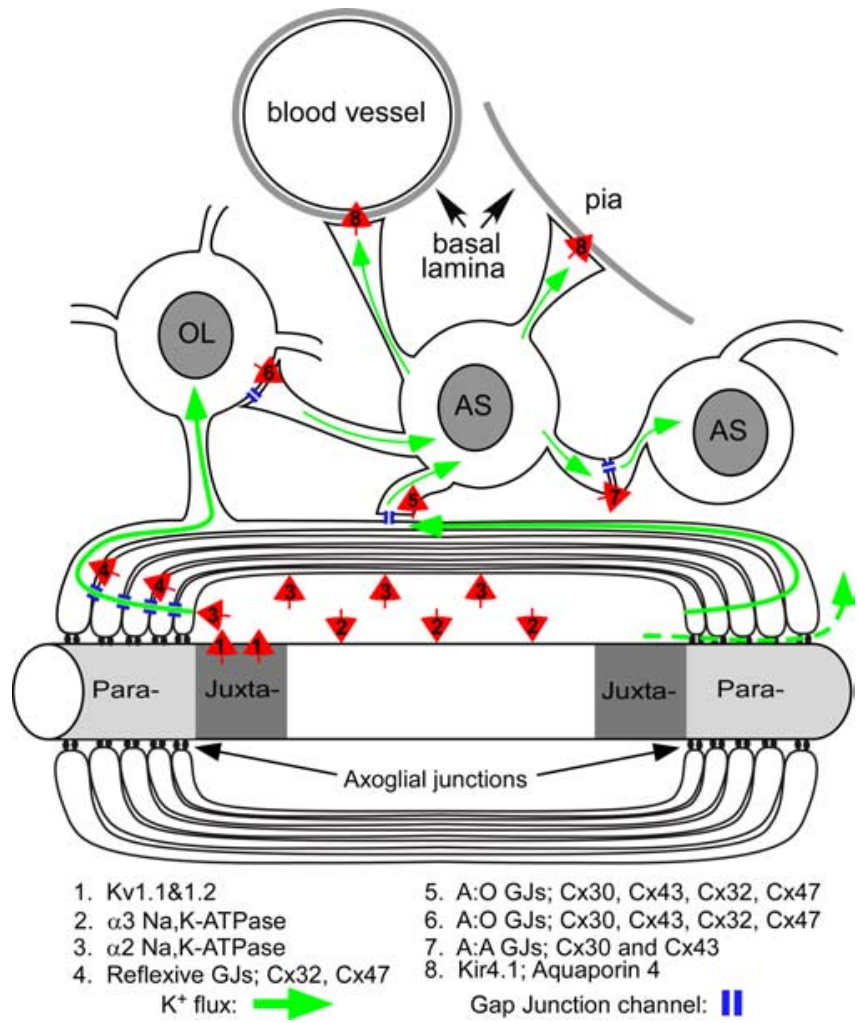

Figure 6. Possible routes for the dispersal of $\mathrm{K}^{+}$released during neuronal activity. Neuronal Kv1.1 and Kv1.2 channels are localized to the junxtaparanodal axolemma (1). Thus, $\mathrm{K}^{+}$ions released through these channels during neuronal activity enter a private extracellular compartment bounded by axoglial junctions at the paranodes. Some $\mathrm{K}^{+}$ions could leak through these junctions, gaining direct access to astrocytes (5) for uptake, but Na-K-ATPases in axolemma (2) and oligodendrocyte plasma membrane (3) likely account for the majority of uptake. Once in the periaxonal cytoplasm of the oligodendrocyte, $\mathrm{K}^{+}$could migrate though reflexive gap junctions located in the paranodal membranes (4) to reach the outer layer of myelin and the oligodendrocyte cell body. Then, $\mathrm{K}^{+}$could gain entry to the astrocyte cytoplasm via heterotypic gap junctions between oligodendrocyte and astrocyte (6). Finally, Kir4.1 channels located in astrocyte end feet at capillaries and the glia limitans (8) would contribute to " $\mathrm{K}{ }^{+}$siphoning" and removal.

a mechanism for dispersal of $\mathrm{K}^{+}$to distal locations, for release by passive mechanisms. The latter include release at capillaries and pia mater via Kir4.1, which is highly concentrated at astrocytic end feet (Newman, 1986; Kofuji and Newman, 2004). Thus, the inclusion of oligodendrocytes into a "glial syncytium" should enhance the ability of CNS glia to redistribute $\mathrm{K}^{+}$.

Double KOs of Cx32 and Cx47 display severe CNS dysmyelination, with prominent vacuolation (Menichella et al., 2003; Odermatt et al., 2003). Although not directly tested, the expectation from immunocytochemical studies (Altevogt and Paul, 2004; Kamasawa et al., 2005) is that loss of both Cx32 and Cx47 would dramatically reduce or eliminate both astrocyte:oligodendrocyte (A:O) coupling and reflexive coupling between oligodendrocyte cell body and periaxonal cytoplasm. The finding that Kir4.1-null mice also developed vacuoles in myelinated regions suggested that $\mathrm{A}: \mathrm{O}$ coupling and/or oligodendrocyte reflexive coupling might share a function with Kir4.1, a notion supported by genetic complementation in which vacuolation was observed in compound connexin-Kir4.1 heterozygotes $\left(C \times 32^{-/ Y}, C \times 47^{+/-}\right.$, Kir4.1 $1^{+/-}$). We propose that the vacuoles are a pathological accumulation of ions and $\mathrm{H}_{2} \mathrm{O}$ that are unable to redistribute in the mutant mice. The vacuoles in $\mathrm{Cx} 32 / \mathrm{Cx} 47 \mathrm{dKO}\left(\right.$ Kir4. $\left.1^{+/+}\right)$mice are mostly in the periaxonal space, between the axon and the myelin sheath. Because reflexive coupling should be strongly affected, these vacuoles could result from an inability to redistribute the $\mathrm{K}^{+}$released through Shaker-type Kv1.1 and Kv1.2 channels into the periaxonal space (Wang et al., 1993; Devaux et al., 2002).

In contrast, vacuoles in both Kir4.1 ${ }^{-1-}$ and $C \times 32^{-/ Y}$ $\mathrm{C} \times 47^{+/-}, \mathrm{Kir} 4.1^{+/-}$mice develop mostly in association with the outside of the myelin sheaths. This ultrastructural difference could reflect a difference in the locations of $\mathrm{K}^{+}$accumulation. In $\mathrm{C} \times 32^{-/ \mathrm{Y}}, \mathrm{C} \times 47^{+/-}$, Kir4 $.1^{+/-}$mice, $\mathrm{K}^{+}$efflux from oligodendrocyte perikarya might be more affected than in the connexin $\mathrm{dKO}$ because both direct $\mathrm{K}^{+}$release through Kir4.1 (Kalsi et al., 2004) and transfer to astrocytes through gap junctions would be impacted. The $C \times 32^{-/ Y}, C x 47^{+/-}$, Kir4.1 $1^{+/-}$oligodendrocytes would experience somewhat increased $\left[\mathrm{K}^{+}\right]$in several compartments rather than a large increase mainly in the periaxonal space as we postulate for the connexin $\mathrm{dKO}$. The appearance of vacuolation associated with the outside rather than the inside of the myelin sheath in $C \times 32^{-/ Y}$ $\mathrm{C} \times 47^{+/-}, \mathrm{Kir} 4.1^{+/-}$animals could reflect a greater sensitivity of this compartment to elevations in $\left[\mathrm{K}^{+}\right]$. This model is consistent with the known localization of $\mathrm{Cx} 32$ and $\mathrm{Cx} 47$ at both paranodal regions and perikarya (Menichella et al., 2003; Kamasawa et al., 2005) and Kir4.1 predominantly in oligodendrocyte perikarya and astrocyte end feet (Kalsi et al., 2004).

Our data suggest that, in addition to their well known role in facilitating saltatory conduction, oligodendrocytes have an important function in spatial buffering of $\mathrm{K}^{+}$released during axonal activity. A:O and reflexive coupling may also be important in pathological states, because proper $\mathrm{K}^{+}$and water homeostasis affect epileptogenesis (Dudek et al., 1998; Hinterkeuser et al., 2000; Steinhauser and Seifert, 2002; Amiry-Moghaddam et al., 2003; Eid et al., 2005). Perhaps diminished $\mathrm{K}^{+}$buffering contributes to the seizures that are seen in human patients and mouse models in which oligodendrocyte function is compromised, including those lacking connexin genes (Sidman et al., 1964, 1985; Young et al., 1989; Wang et al., 2001; Eriksson et al., 2002; Menichella et al., 2003; Odermatt et al., 2003; Uhlenberg et al., 2004). We propose that oligodendrocytes are part of the network of cells that redistribute extracellular $\mathrm{K}^{+}$ generated during activity and could serve as a novel therapeutic target for diseases related to excessive excitability.

\section{References}

Altevogt BM, Paul DL (2004) Four classes of intercellular channels between glial cells in the CNS. J Neurosci 24:4313-4323.

Altevogt BM, Kleopa KA, Postma FR, Scherer SS, Paul DL (2002) Connexin29 is uniquely distributed within myelinating glial cells of the central and peripheral nervous systems. J Neurosci 22:6458-6470.

Amiry-Moghaddam M, Williamson A, Palomba M, Eid T, de Lanerolle NC, Nagelhus EA, Adams ME, Froehner SC, Agre P, Ottersen OP (2003) Delayed $\mathrm{K}^{+}$clearance associated with aquaporin- 4 mislocalization: phenotypic defects in brains of alpha-syntrophin-null mice. Proc Natl Acad Sci USA 100:13615-13620.

Arroyo EJ, Scherer SS (2000) On the molecular architecture of myelinated fibers. Histochem Cell Biol 113:1-18.

Balice-Gordon RJ, Bone LJ, Scherer SS (1998) Functional gap junctions in the Schwann cell myelin sheath. J Cell Biol 142:1095-1104.

Bansal A, Singer JH, Hwang BJ, Xu W, Beaudet A, Feller MB (2000) Mice lacking specific nicotinic acetylcholine receptor subunits exhibit dramatically altered spontaneous activity patterns and reveal a limited role for retinal waves in forming $\mathrm{ON}$ and OFF circuits in the inner retina. J Neurosci 20:7672-7681.

Bergoffen J, Scherer SS, Wang S, Scott MO, Bone LJ, Paul DL, Chen K, Lensch MW, Chance PF, Fischbeck KH (1993) Connexin mutations in X-linked Charcot-Marie-Tooth disease. Science 262:2039-2042.

Castren E, Zafra F, Thoenen H, Lindholm D (1992) Light regulates expression of brain-derived neurotrophic factor mRNA in rat visual cortex. Proc Natl Acad Sci USA 89:9444-9448. 
Connors BW, Ransom BR, Kunis DM, Gutnick MJ (1982) Activitydependent $\mathrm{K}^{+}$accumulation in the developing rat optic nerve. Science 216:1341-1343.

Corriveau RA, Huh GS, Shatz CJ (1998) Regulation of class I MHC gene expression in the developing and mature CNS by neural activity. Neuron 21:505-520.

David G, Barrett JN, Barrett EF (1993) Activation of internodal potassium conductance in rat myelinated axons. J Physiol (Lond) 472:177-202.

Demerens C, Stankoff B, Logak M, Anglade P, Allinquant B, Couraud F, Zalc B, Lubetzki C (1996) Induction of myelination in the central nervous system by electrical activity. Proc Natl Acad Sci USA 93:9887-9892.

Devaux J, Gola M, Jacquet G, Crest M (2002) Effects of $\mathrm{K}^{+}$channel blockers on developing rat myelinated CNS axons: identification of four types of $\mathrm{K}^{+}$channels. J Neurophysiol 87:1376-1385.

Devaux JJ, Kleopa KA, Cooper EC, Scherer SS (2004) KCNQ2 is a nodal $\mathrm{K}^{+}$ channel. J Neurosci 24:1236-1244.

Dudek FE, Yasumura T, Rash JE (1998) "Non-synaptic" mechanisms in seizures and epileptogenesis. Cell Biol Int 22:793-805.

Eid T, Lee TS, Thomas MJ, Amiry-Moghaddam M, Bjornsen LP, Spencer DD, Agre P, Ottersen OP, de Lanerolle NC (2005) Loss of perivascular aquaporin 4 may underlie deficient water and $\mathrm{K}^{+}$homeostasis in the human epileptogenic hippocampus. Proc Natl Acad Sci USA 102:1193-1198.

Eriksson M, Ben Menachem E, Andersen O (2002) Epileptic seizures, cranial neuralgias and paroxysmal symptoms in remitting and progressive multiple sclerosis. Mult Scler 8:495-499.

Fink D, Knapp PE, Mata M (1996) Differential expression of Na,K-ATPase isoforms in oligodendrocytes and astrocytes. Dev Neurosci 18:319-326.

Hinterkeuser S, Schroder W, Hager G, Seifert G, Blumcke I, Elger CE, Schramm J, Steinhauser C (2000) Astrocytes in the hippocampus of patients with temporal lobe epilepsy display changes in potassium conductances. Eur J Neurosci 12:2087-2096.

Kalsi AS, Greenwood K, Wilkin G, Butt AM (2004) Kir4.1 expression by astrocytes and oligodendrocytes in CNS white matter: a developmental study in the rat optic nerve. J Anat 204:475-485.

Kamasawa N, Sik A, Morita M, Yasumura T, Davidson KG, Nagy JI, Rash JE (2005) Connexin-47 and connexin-32 in gap junctions of oligodendrocyte somata, myelin sheaths, paranodal loops and Schmidt-Lanterman incisures: implications for ionic homeostasis and potassium siphoning. Neuroscience 136:65-86.

Kofuji P, Newman EA (2004) Potassium buffering in the central nervous system. Neuroscience 129:1045-1056.

Lein ES, Shatz CJ (2000) Rapid regulation of brain-derived neurotrophic factor mRNA within eye-specific circuits during ocular dominance column formation. J Neurosci 20:1470-1483.

MacVicar BA, Feighan D, Brown A, Ransom B (2002) Intrinsic optical signals in the rat optic nerve: role for $\mathrm{K}^{+}$uptake via NKCC1 and swelling of astrocytes. Glia 37:114-123.

Massa PT, Mugnaini E (1982) Cell junctions and intramembrane particles of astrocytes and oligodendrocytes: a freeze-fracture study. Neuroscience 7:523-538.

McGrail KM, Phillips JM, Sweadner KJ (1991) Immunofluorescent localization of three $\mathrm{Na}$, K-ATPase isozymes in the rat central nervous system: both neurons and glia can express more than one Na,K-ATPase. J Neurosci 11:381-391.

Menichella DM, Goodenough DA, Sirkowski E, Scherer SS, Paul DL (2003) Connexins are critical for normal myelination in the CNS. J Neurosci 23:5963-5973.

Nagy JI, Ionescu AV, Lynn BD, Rash JE (2003) Connexin29 and connexin32 at oligodendrocyte and astrocyte gap junctions and in myelin of the mouse central nervous system. J Comp Neurol 464:356-370.

Neusch C, Rozengurt N, Jacobs RE, Lester HA, Kofuji P (2001) Kir4.1 potassium channel subunit is crucial for oligodendrocyte development and in vivo myelination. J Neurosci 21:5429-5438.

Neusch C, Weishaupt JH, Bahr M (2003) Kir channels in the CNS: emerging new roles and implications for neurological diseases. Cell Tissue Res 311:131-138.

Newman EA (1986) High potassium conductance in astrocyte endfeet. Science 233:453-454.

Nielsen S, Nagelhus EA, Amiry-Moghaddam M, Bourque C, Agre P, Ottersen OP (1997) Specialized membrane domains for water transport in glial cells: high-resolution immunogold cytochemistry of aquaporin-4 in rat brain. J Neurosci 17:171-180.
Odermatt B, Wellershaus K, Wallraff A, Seifert G, Degen J, Euwens C, Fuss B, Bussow H, Schilling K, Steinhauser C, Willecke K (2003) Connexin 47 (Cx47)-deficient mice with enhanced green fluorescent protein reporter gene reveal predominant oligodendrocytic expression of $\mathrm{Cx} 47$ and display vacuolized myelin in the CNS. J Neurosci 23:4549-4559.

Orkand RK, Nicholls JG, Kuffler SW (1966) Effect of nerve impulses on the membrane potential of glial cells in the central nervous system of amphibia. J Neurophysiol 29:788-806.

Pan Z, Kao T, Horvath Z, Lemos J, Sul JY, Cranstoun SD, Bennett V, Scherer SS, Cooper EC (2006) A common ankyrin-G-based mechanism retains KCNQ and $\mathrm{NaV}$ channels at electrically active domains of the axon. J Neurosci 26:2599-2613.

Penn AA, Riquelme PA, Feller MB, Shatz CJ (1998) Competition in retinogeniculate patterning driven by spontaneous activity. Science 279:2108-2112.

Ransom BR, Yamate CL, Connors BW (1985) Activity-dependent shrinkage of extracellular space in rat optic nerve: a developmental study. J Neurosci 5:532-535.

Ransom CB, Ransom BR, Sontheimer H (2000) Activity-dependent extracellular $\mathrm{K}^{+}$accumulation in rat optic nerve: the role of glial and axonal $\mathrm{Na}^{+}$pumps. J Physiol (Lond) 522:427-442.

Rash JE, Yasumura T, Dudek FE, Nagy JI (2001) Cell-specific expression of connexins and evidence of restricted gap junctional coupling between glial cells and between neurons. J Neurosci 21:1983-2000.

Scherer SS, Deschenes SM, Xu YT, Grinspan JB, Fischbeck KH, Paul DL (1995) Connexin32 is a myelin-related protein in the PNS and CNS. J Neurosci 15:8281-8294.

Schoups AA, Elliott RC, Friedman WJ, Black IB (1995) NGF and BDNF are differentially modulated by visual experience in the developing geniculocortical pathway. Brain Res Dev Brain Res 86:326-334.

Sidman RL, Dickie MM, Appel SH (1964) Mutant mice (Quaking and Jimpy) with deficient myelination in the central nervous system. Science 144:309-311.

Sidman RL, Conover CS, Carson JH (1985) Shiverer gene maps near the distal end of chromosome 18 in the house mouse. Cytogenet Cell Genet 39:241-245.

Skoff RP, Toland D, Nast E (1980) Pattern of myelination and distribution of neuroglial cells along the developing optic system of the rat and rabbit. J Comp Neurol 191:237-253.

Steinhauser C, Seifert G (2002) Glial membrane channels and receptors in epilepsy: impact for generation and spread of seizure activity. Eur J Pharmacol 447:227-237.

Stellwagen D, Shatz CJ (2002) An instructive role for retinal waves in the development of retinogeniculate connectivity. Neuron 33:357-367.

Stryker MP, Harris WA (1986) Binocular impulse blockade prevents the formation of ocular dominance columns in cat visual cortex. J Neurosci 6:2117-2133.

Taylor RA, Simon EM, Marks HG, Scherer SS (2003) The CNS phenotype of $\mathrm{X}$-linked Charcot-Marie-Tooth disease: more than a peripheral problem. Neurology 61:1475-1478.

Thellin O, Zorzi W, Lakaye B, De Borman B, Coumans B, Hennen G, Grisar T, Igout A, Heinen E (1999) Housekeeping genes as internal standards: use and limits. J Biotechnol 75:291-295.

Uhlenberg B, Schuelke M, Ruschendorf F, Ruf N, Kaindl AM, Henneke M, Thiele H, Stoltenburg-Didinger G, Aksu F, Topaloglu H, Nurnberg P, Hubner C, Weschke B, Gartner J (2004) Mutations in the gene encoding gap junction protein alpha 12 (connexin 46.6) cause PelizaeusMerzbacher-like disease. Am J Hum Genet 75:251-260.

Vabnick I, Shrager P (1998) Ion channel redistribution and function during development of the myelinated axon. J Neurobiol 37:80-96.

Wang H, Kunkel DD, Martin TM, Schwartzkroin PA, Tempel BL (1993) Heteromultimeric $\mathrm{K}^{+}$channels in terminal and juxtaparanodal regions of neurons. Nature 365:75-79.

Wang PJ, Hwu WL, Shen YZ (2001) Epileptic seizures and electroencephalographic evolution in genetic leukodystrophies. J Clin Neurophysiol 18:25-32.

Waxman SG, Black JA (1984) Freeze-fracture ultrastructure of the perinodal astrocyte and associated glial junctions. Brain Res 308:77-87.

Young W, Rosenbluth J, Wojak JC, Sakatani K, Kim H (1989) Extracellular potassium activity and axonal conduction in spinal cord of the myelindeficient mutant rat. Exp Neurol 106:41-51. 